\title{
The first SGMA groundwater market is trading: The importance of good design and the risks of getting it wrong
}

\author{
Groundwater markets are a promising tool for basins implementing SGMA, but they are complex, \\ and good design is essential.
}

Sarah Heard, Director, MarketLab, The Nature Conservancy

Matthew Fienup, Executive Director, Center for Economic Research and Forecasting, and Assistant Professor, California Lutheran University

E. J. Remson, Senior Project Director, California Water Program, The Nature Conservancy

Online: https://doi.org/10.3733/ca.2021a0010

\begin{abstract}
$\Lambda$ groundwater market, which caps total pumping within one or more basins, allocates portions of the total to individual users and allows users to buy and sell groundwater under the total cap, is a promising tool for basins implementing California's Sustainable Groundwater Management Act (SGMA). While the benefits of a cap-and-trade system for both groundwater users and regulators are potentially very large, so too are the risks. An electronic bulletin board that introduces buyers and sellers, like craigslist.org, is not a market. Nor is a sophisticated financial application that matches participants and executes financial transactions. A water market is a complex interaction of individuals and institutions the product of a large number of people, structures, operational mechanisms and rules. Without careful design, a water market can do harm.
\end{abstract}

Creating a functioning market is not easy. There is no off-the-shelf solution, and there is a lot to get right. The most important - and difficult - elements to get right are the rules and structure, which must be tailored to local conditions. Capping and monitoring pumping, generating buy-in from diverse stakeholders and guarding against cheating and adverse impacts, such as the drying of shallow drinking water wells or of groundwater-dependent ecosystems (GDEs), are also essential. Even with careful design, markets can fall short or cause adverse impacts. And, as the new reality of pumping restrictions sets in, powerful pumpers, largely unregulated before SGMA, will attempt to bend market rules in their favor.

We have lived this experience. Since 2016, we have been in the trenches, developing the Fox

The Fox Canyon groundwater market operates in a large area of Ventura County that includes over 55,000 acres of high-value agricultural land and 500 active agricultural wells. A primary driver of the market is the scarcity of water. 


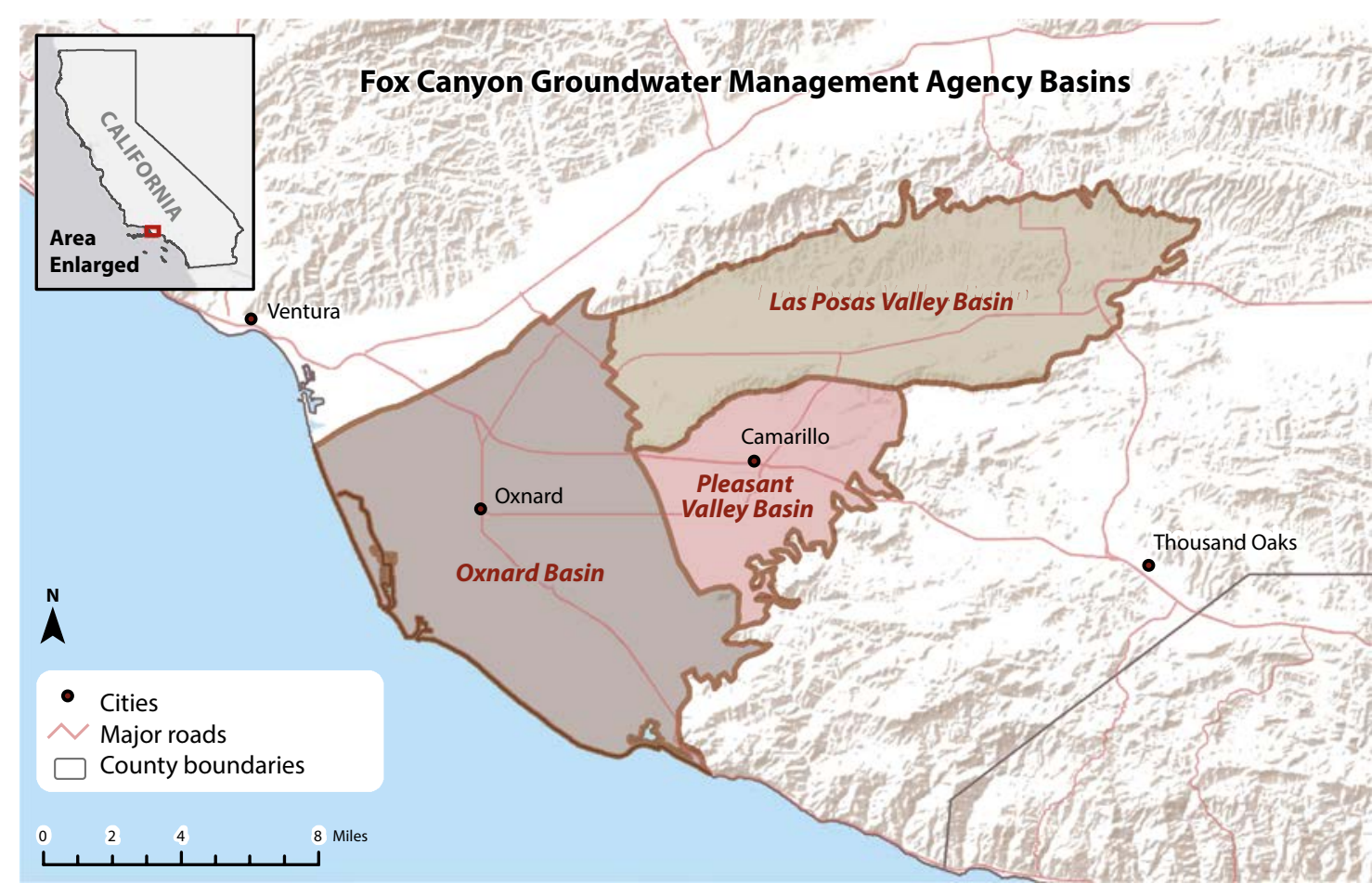

Canyon groundwater market for three coastal basins, an area known as Fox Canyon, in Ventura County. The first market to be implemented under SGMA, the Fox Canyon groundwater market began trading in early 2020 in the Oxnard basin, which has nearly 200 agricultural wells representing 77,000 acre-feet of pumping. Ventura County is one of the nation's most productive agricultural counties, with $\$ 2$ billion in agricultural revenue, the majority of which is generated in Fox Canyon (County of Ventura 2019). Water users there are largely groundwater-dependent, and decades of overpumping landed two of the region's basins on the list of 21 SGMA-designated "critically overdrafted basins."

Area growers called for a groundwater market as a tool that would give them flexibility while complying with pumping cuts of $40 \%$ or more under SGMA. What began as an open, robust stakeholder process chartered by the Fox Canyon Groundwater Management Agency (FCGMA), led by California Lutheran University (CLU) and supported by The Nature Conservancy (TNC), grew into a multiyear effort to create a model groundwater market under SGMA.

\section{Enabling conditions}

Our experience developing the Fox Canyon groundwater market and that of other basins in the United States and overseas indicates that groundwater markets can be a useful tool for achieving basin sustainability, but they are not a good fit for every basin or groundwater sustainability agency (GSA). A number of enabling conditions are necessary to ensure that a groundwater market functions effectively. The Fox
Canyon groundwater market benefitted from the four enabling conditions (water scarcity, fixed allocations, agricultural stakeholder support, and capacity and funding) described below.

\section{Water scarcity}

Without significant scarcity, a market will not function and is likely not needed. A primary driver of the Fox Canyon groundwater market is the degree of scarcity that agricultural users are experiencing as they implement the SGMA-mandated reduction in pumping. SGMA's requirement that a basin's sustainable yield be determined fixes the maximum amount of groundwater available for the diverse needs of all pumpers in that basin, essentially serving as a cap on total extractions. If the demand for groundwater exceeds the sustainable yield of the basin, reductions in individual pumping are likely required, as they were in Fox Canyon.

\section{Fixed allocations}

Clearly defined individual fixed allocations are the first step in the development of a cap-and-trade market; they determine the unit of trade and establish how many units each market participant has to either extract or trade. The sum of the fixed allocations equals the total extraction allowed for the basin in a given year.

FCGMA chose to move from an existing system of pumping allocations that varied by crop type, known as indexed, or efficiency, allocations, to an allocation system based on historical pumping for each well. Water-market participants are assigned pumping allocations in units of 1 acre-foot, to be used or traded during the current water year.
Fox Canyon Groundwater Management Agency (FCGMA) is a Special Act District created by the California legislature in 1982 to address seawater intrusion in three coastal basins in Ventura County. FCGMA was officially designated as the groundwater sustainability agency (GSA) for the three basins with the passage of the Sustainable Groundwater Management Act (SGMA) in 2014. Fox Canyon growers are facing pumping cuts of $40 \%$ or more under SGMA. 


\section{Agricultural stakeholder support}

Agricultural stakeholder support for a groundwater market is essential, as farmers represent the largest consumers of groundwater in California. The idea for the Fox Canyon groundwater market originated among a small group of local growers in early 2014, as they were facing the prospect of reduced groundwater supplies as the result of California's drought. Growers recognized that the heterogeneity in both the season and the water demand of the region's crops (ranging from berries, flowers and vegetables to citrus and avocado orchards) created opportunities for a water market (see Fargher 2011). With the help of the Farm Bureau of Ventura County, they brought their ideas to FCGMA's staff and board of directors. Agricultural stakeholders in FCGMA's jurisdiction are well-organized, and the leadership provided by this group was critical.

\section{Capacity and funding}

The creation of a water market is a considerable undertaking that requires significant funding and dedicated capacity from GSA staff, participants and partners. During the development of the Fox Canyon groundwater market, TNC secured a Conservation Innovation Grant from the federal Natural Resources Conservation Service, with the support of FCGMA, CLU, the Farm Bureau of Ventura County and local growers. The primary motivation for pursuing the grant was to help implement a sound groundwater sustainability plan (GSP) with an embedded groundwater market that would provide for the needs of both nature and agriculture and that would hopefully serve as a model for others to follow.

The grant provided over $\$ 1$ million to design in Fox Canyon - flowers, vegetables, berries, citrus, avocado - creates diversity in water demand, which suits a groundwater market. market may not have endured the resource-intensive development and testing phases.

\section{What good looks like}

Establishing a functioning water market involves far more than creating a trading platform. At a minimum, a successful water market requires clear objectives, rules to achieve those objectives and a governance system with resources and the capacity to establish and enforce the rules. For nearly 2 years, a range of stakeholders worked collaboratively to develop the Fox Canyon groundwater market's goals and objectives, rules and operational mechanisms. These were carefully tailored to fit local conditions and the needs of local stakeholders, which is a big part of good design. Well-designed markets in other jurisdictions may look different in some aspects.

\section{Solid groundwater sustainability plan}

A GSA wishing to create a water market should create its GSP with the market in mind. A well-designed water market can help achieve the goals of a GSP, but a poorly designed market may undermine the plan. Likewise, superior market design cannot mitigate a GSP's shortcomings. FCGMA created its GSP and water market in parallel. That required significant agency capacity and resources but allowed for iteration between the GSP and the market design so that critical elements of the GSP, such as the sustainable yield and pumping allocations, could support a functioning water market.

Methods to achieve pumping reductions that are overly complex or are not clearly quantifiable on a wellby-well basis may not be compatible with a market. For example, some Fox Canyon growers proposed a rule to allow "borrowing from the future" (pumping beyond a current year's allocation, to be offset by further reductions in future years), but borrowing would undermine the basic structure and function of the market by destroying the price signal upon which individual wateruse decisions are made. Without proper attention, plan elements may exclude the possibility of a market. A solid GSP should also establish what is not traded.

Specifically, water within the sustainable yield should provide for human consumption and GDEs; communities and nature should not be required to rely on groundwater markets to meet their water needs. Environmental groups, disadvantaged communities (DACs) and environmental justice organizations throughout California are right to be concerned that water-market activity may be dominated by those with the greatest financial resources or political power, that local groundwater allocations may be allocated disproportionately to these powerful groups and that adverse impacts, such as drying of DACs' shallow drinking water wells or loss of GDEs, may result. These are real risks, and the remedy is a strong GSP that balances economic, environmental and social benefits to ensure compliance with SGMA. 


\section{Open, public process}

An open process and robust stakeholder input on the creation of a water market are essential in building trust, customizing the structure of the market and market rules and ensuring that stakeholders use the market. FCGMA established a formal stakeholder group, called the Water Market Group, with biweekly meetings that were open to the public, encouraging input on the market design. CLU facilitated the meetings, which typically had 40 to 50 participants, including growers and representatives from water utilities, municipalities with nearly a half-million residents, mutual water companies and environmental organizations.

The meetings focused on learning how water markets function, setting goals for the Fox Canyon groundwater market and establishing trading rules. To help build local knowledge on how water markets work, CLU invited guest speakers with market experience from around the world to address the group. The group also gathered data, case studies and other publications on water markets, and it posted this information on a shared website. A key theme that emerged from the presentations and literature review was the importance of creating a water market that was transparent, fair, easy to understand and low-cost.

After meeting for 7 months, the group unanimously agreed on the outline for the structure and operational mechanisms of a permanent water market as well as on a set of goals and rules to be used in a series of pilot water markets. The group presented these rules to FCGMA's staff and board of directors, and they became the basis for the agency's ordinances that authorized the water market. A series of pilots tested these rules before the market was opened to all agricultural pumpers in the Oxnard basin in February 2020. The group will re-engage, as needed, to address any issues identified and to recommend changes to the rules as the market evolves over time.

\section{Protections against market power}

Well-designed markets provide all market participants with equal access to trade and equal opportunity to gain from market activity. This necessitates keeping transaction costs low and creating a fair market that is free of manipulation. Influential parties may attempt to manipulate the price of water and to extract all of the economic gains from trade. They may even seek to exclude others from participating in the market fully. For example, during an early pilot of the Fox Canyon groundwater market, a packer/shipper sought to learn the identities of all growers in the market in order to restrict their participation. Rules and structures

Biweekly meetings facilitated by CLU brought together growers and representatives from water utilities, municipalities, mutual water companies, and environmental organizations. A solid agreement emerged that the market needed to be transparent, fair, easy to understand, and low cost.

\section{Benefits of well-designed markets}

$A_{t}$ well-designed groundwater market, in which the price of water is allowed to reflect its true value, has multiple benefits. Notably, a functioning market is a cost-effective tool for achieving SGMA's mandate of sustainable management, driving the reallocation of pumping within a basin to the highest-value uses. The ability to trade motivates users to conserve scarce groundwater, invest in water use efficiency and develop new water supplies, like recharged wastewater - all of which contribute to basin sustainability. The largest benefits typically occur in regions with both water scarcity and variable water demand, seasonal fluctuations in water availability, a large number of interconnected water users with varying demands and degrees of flexibility, agricultural water users who are exposed to the risks that accompany national and global markets, and increasing demands for urban and environmental water (Fargher 2011).

Markets benefit their users by allowing greater flexibility than commandand-control schemes do. For example, growers can generate revenue when fallowing fields and avoid penalties for pumping beyond their allocation by purchasing additional water on the market. In the Fox Canyon groundwater market's first year of trading, a grower avoided nearly $\$ 350,000$ in surcharges by purchasing the water for less than $15 \%$ of that figure. Municipal and industrial users can turn to markets to purchase additional supplies and to sell surplus supplies, like recharged wastewater, to recoup capital costs. Water trading has proven successful in supporting agricultural productivity in a number of settings, from Australia and South America to the Western United States (Fargher 2011; Hearne and Easter 1997).

A well-designed market can also benefit sensitive resources. Special rules can avoid undesirable impacts in areas that need protection against overpumping. In Fox Canyon, pumping was reduced in one of the most vulnerable areas — a pumping trough — without top-down regulatory restrictions that differentially impacted pumpers in a sensitive area. Other sensitive areas can also be spatially delineated, such as groundwater-dependent ecosystems (GDEs) and shallow drinking water wells for rural and disadvantaged communities (DACs). Water markets have enhanced municipal water security and maximized environmental benefits in areas as diverse as Australia and the Western United States (Fargher 2011; Garrick et al. 2009; Garrick et al. 2011).

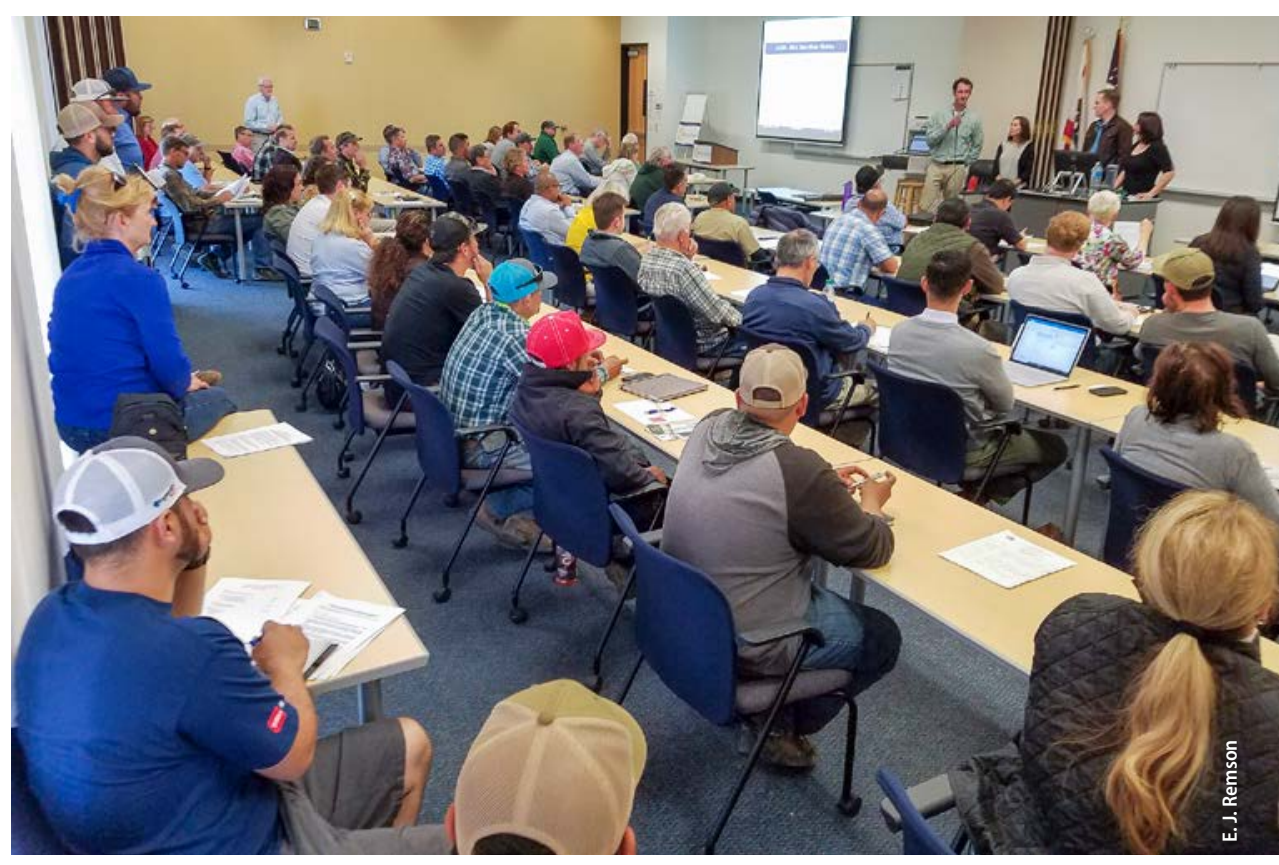




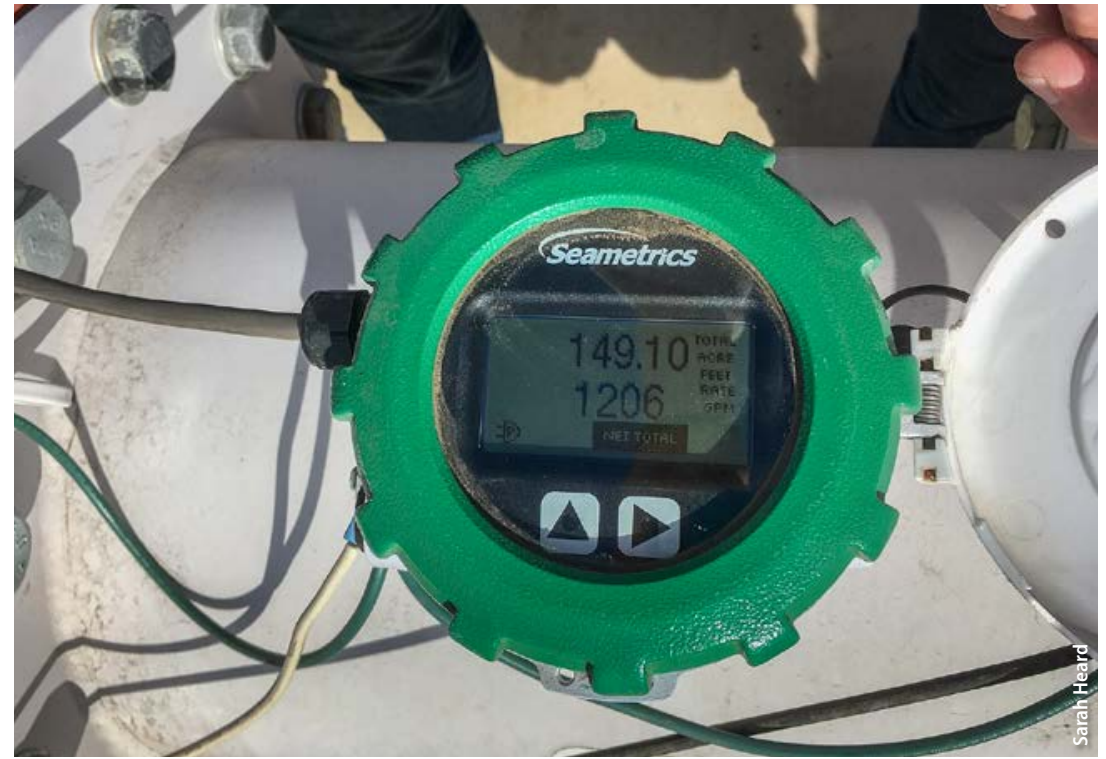

Accurate water monitoring is a first-order concern to ensure functioning groundwater markets. Meters, in place on Fox Canyon groundwater wells since the 1980s, track water use, left. To prevent cheating and ensure accurate data collection, Fox Canyon growers opted for universal telemetric sensors that attach to meters and stream pumping data real-time, funded by a grant from the Natural Resources Conservation Service, right. designed by the Water Market Group, including a single, central exchange and anonymized trading, succeeded in preventing unfair influence.

Equal access to the Fox Canyon groundwater market was addressed by implementing a formal, centralized market structure that uses a private exchange administrator, that is, a private organization that is independent of the GSA. Stakeholders felt strongly that the exchange administrator should be independent of the GSA and also that it should be local and nonprofit and not have a financial or other stake in the reallocation of groundwater pumping.

The goal of a fair market was addressed by establishing an anonymized market and blind, algorithmic matching. Bids and offers are submitted and matched, and transfers of pumping are executed and reported to the GSA, all without market participants ever knowing who the counterparties are. And yet the process is transparent and accountable.

\section{Mitigation of adverse third-party impacts}

Well-designed markets must anticipate and mitigate the risks of adverse third-party impacts. Market transfers can inadvertently create areas of concentrated pumping in the basin that can result in lowered water levels and a decline in water quality, which, in turn, may adversely impact surface water flows, GDEs and other local pumpers. The drinking water supplies of DACs may be particularly vulnerable.

Mitigation starts with a basin's allocation system, for example, ensuring adequate water for GDEs and DACs. Once allocations have been established, foresight is required to anticipate when a particular transfer of allocation might adversely impact third parties. Specific market rules are required to prevent these unintended impacts. It may also be necessary for market rules to adapt over time to address unintended impacts.

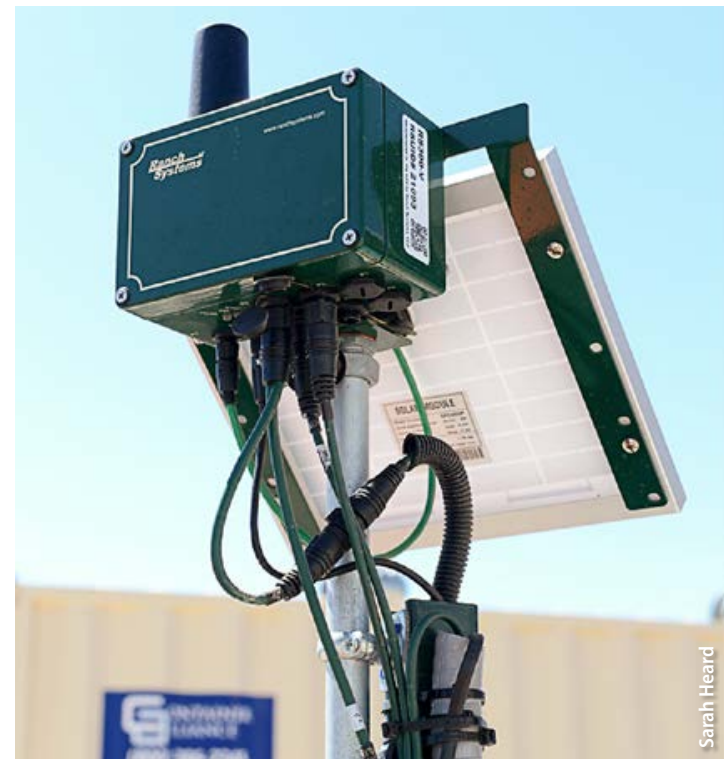

Special management areas (SMAs) are delineated geographic areas established by the GSP to address the risk that trading may negatively impact groundwater quality or levels. Rules can be implemented to restrict the volume or direction of water transfers within an SMA. SMAs have broad applications and can be used to address adverse impacts to surface water flows, GDEs and DACs.

The Fox Canyon groundwater market includes two SMAs; one is an area of seawater intrusion, the other is a local pumping trough. The Fox Canyon groundwater market's rules stipulate that pumpers in an SMA may purchase additional water only from another pumper within the SMA but that they may sell either to a pumper within the same SMA or to a pumper outside of both SMAs. The goal of these directional restrictions is to ensure that transfers of pumping allocation do not result in a net increase in pumping within an SMA. In practice, the use of this tool has resulted in a market transfer of pumping out of one SMA into a healthier part of the basin.

Directional trading is one of a number of approaches used to protect SMAs. Exchange rates, or trading ratios, whereby one unit of pumping outside an SMA is traded for less than a unit of pumping within an SMA, have also been used in other markets.

\section{Accurate, reliable monitoring of extraction}

Accurate water-use data is critical to achieving sustainable groundwater management. Errors in the measurement of water use have been shown to produce large economic losses for farmers and to undermine policies to limit adverse impacts on the environment and other water users. Choosing monitoring technology involves trade-offs, notably between implementation cost and accuracy; one of the least costly options, satellite remote sensing, has been shown to produce large measurement errors (Foster et al. 2020). 
A water market also needs accurate water-use data to ensure that participants trade only unused water allocations and that no exceedances of pumping allocations result from trading. Accurate monitoring is a first-order concern for water market participants. Any underreporting of water use, or other form of cheating, devalues allocations available for trade on the market and undermines progress toward achieving a basin's sustainable yield, potentially resulting in further cuts down the road.

In Fox Canyon, growers were deeply concerned that pumping be accurately measured and so they proposed universal telemetric monitoring of groundwater extraction with automated reporting. Fox Canyon pumpers now use cellular-based telemetry attached to individual meters; this system broadcasts pumping data to a cloud-based data portal. The portal automatically submits monthly pumping totals to the GSA. Hardware approved for use in Fox Canyon also includes validation measures designed to prevent cheating.

In the early 2000s, FCGMA's staff and board of directors had discussed a requirement that all agricultural wells employ electronic monitoring and automated reporting, using early telemetry hardware, but protest from the agricultural community was so strong that the plan was abandoned. The new Fox Canyon groundwater market altered incentives, making universal telemetric monitoring of extractions not just politically feasible but imperative to agricultural water users.

\section{Market testing: learning and adaptation}

Water markets are complex. They involve an almost dizzying interaction of individuals, institutions, actions and reactions. Critical questions arise for those implementing markets: How will progress be evaluated? Does the market work as intended? What are the unintended consequences? Does the market structure adapt to new information as it becomes available? Answering these questions requires a humble approach: starting simple, testing early and often and creating a market structure that allows for adaptation over time.

During the design phase, the Water Market Group recommended testing the market, with a definitive starting and ending point, to ensure that the market functioned as intended. The goal was to test the rules and any intended market outcomes while also allowing FCGMA and market participants to discover and address any unintended consequences of trading. A series of sequential pilots was implemented. The phases included a demonstration project for the telemetric monitoring and automated reporting system, stress testing of the market rules and the electronic trading platform and trading between pumpers in the largest basin. Numerous issues were identified and addressed prior to full market implementation. Had these issues not been addressed early, they may have forever undermined participants' faith in the market and its ability to function.

\section{Why markets fail}

$T^{\mathrm{h}} \mathrm{c}$ he benefits of water trading can be reduced by a number of factors, including regulatory uncertainty, such as changes to rules or allocations that undermine participants' ability to trade (Grainger and Costello 2014); high transaction costs (Crase et al. 2000; Donoso 2006); the use of market power by one or more participants to restrict access to the market or to manipulate the price of water (Ansink and Houba 2012; Brozović 2016; Bruno and Sexton 2020) and adverse impacts to third parties (Heaney et al. 2006).

As the most important and most common sources of friction in markets, transaction costs and market power warrant special consideration. Transaction costs, which in extreme situations can be greater than the cost of the water itself, include the costs of bringing together willing buyers and sellers of water, negotiating the price and other terms of a trade, validating ownership of the water use right, legalizing the contract, enforcing contract provisions and gaining regulatory approval for a transfer (Crase et al. 2000; Donoso 2006).

A participant exerting market power might benefit from driving the price artificially low (if they plan to buy) or artificially high (if they plan to sell). Even a small degree of exerted market power can cause sizeable impacts (Bruno and Sexton 2020). It can deter potential users, either directly or indirectly, from participating and can increase the risk of the market languishing or even collapsing.

Trust in and the perceived fairness of a market are particularly important. In a number of markets involving agricultural water users, farmers have been shown to forego participation, despite direct financial benefits, due to a lack of trust. Historical mistrust of regulators and other actors, along with fear that the benefits and responsibilities are not equally distributed, are primary causes of an unwillingness to participate (Breetz et al. 2005).

\section{A call to action}

Groundwater markets existed in California, and elsewhere, long before SGMA. But with SGMA's new mandate to achieve basin sustainability across large parts of the state, interest in groundwater markets is growing. According to California's Department of Water Resources, 20 of 46 GSPs submitted to date include a groundwater market as a strategy or management action. Markets are complex by their very nature and have steep learning curves. We have learned firsthand the importance of careful design, how much there is to get right and how much work is involved.

If markets are to be a successful tool in complying with SGMA, GSAs will need support and accountability. If not, too much will be left hanging in the balance. Specifically, we recommend:

1. A standardized framework. Without the support of a guiding, standardized framework on "what good looks like," the risks of market failure and adverse impacts are too high. Currently, GSAs may develop markets as they wish; there are no required elements, like stakeholder involvement or accurate measurement. The standardized framework should articulate the essential elements of a well-functioning market under SGMA - in a broadly applicable, rather than prescriptive, way - so that any GSA could use it to tailor the design of a market to its 
If a groundwater market is trusted by its participants and well used, it's a promising tool to rebalance an overdrawn aquifer. But markets need support and accountability to make sure they succeed.

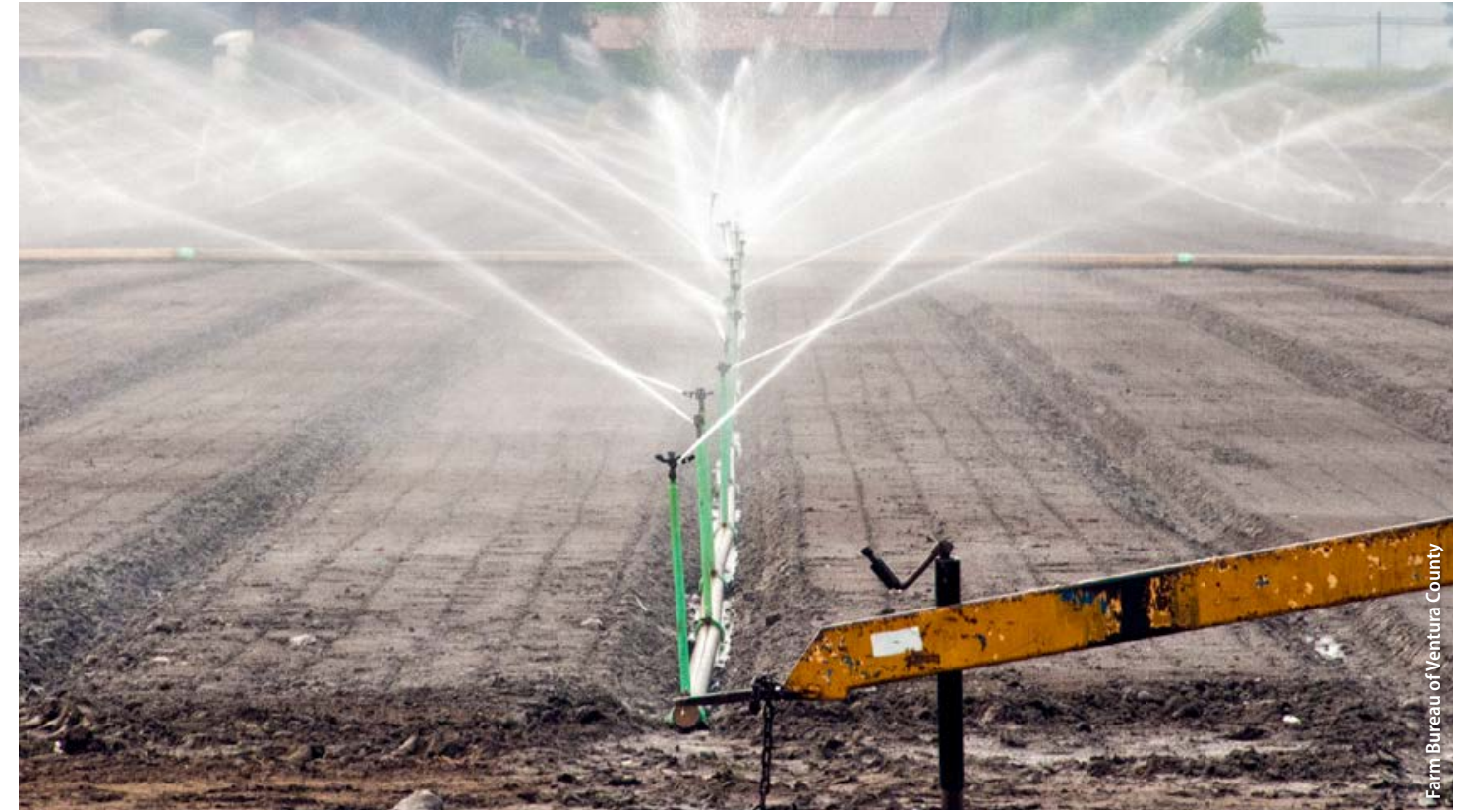

basin's conditions. One possible framework might be an accreditation program administered by an independent body composed of experts in market design.

2. Resources for market development. In addition to a standardized framework, funding and technical expertise are essential to produce functioning markets. State funding for additional staff capacity and outside expertise would help guard against the development of poorly designed markets that are set up to fail.

3. Accountability. Once they have the right ingredients to produce "good markets" - a standardized framework, funding and technical expertise - GSAs must then be held accountable for the outcomes of implementing groundwater markets. Markets don't end at design; they need regular evaluation to ensure that they function as intended. They should be adapted if they underperform or cause adverse impacts. Evaluating and reporting on the outcomes of implementing groundwater markets are not currently required but should be required going forward.

Groundwater markets hold great promise as we seek to rebalance our aquifers, but only if they are recognized for the complex tools that they are. It is still early enough to ensure that groundwater markets take shape in a way that helps implement, rather than undermines, SGMA's objectives. The risk of failure is great, and, if we fail, we may see little progress on SGMA or, worse, an exacerbation of already dire aquifer conditions. CA

\section{References}

Ansink E, Houba H. 2012. Market power in water markets. J Environ Econ Manag 64(2):237-52.

Breetz HL, Fisher-Vanden K, Jacobs H, Schary C. 2005

Trust and communication: Mechanisms for increasing farmers' participation in water quality trading. Land Econ 81(2):170-90.

Brozović N. 2016. Presentation to the Fox Canyon Water Market Group. Water for Food Institute, University of Nebraska. Apr. 24-26, 2016. Lincoln, NE.

Bruno EM, Sexton RJ. 2020. The gains from agricultural groundwater trade and the potential for market power: Theory and application. Am J Agr Econ 102(3):884-910.
County of Ventura. 2019.

Ventura County's 2019 Crop \& Livestock Report. Office of the Ventura County Agricultural Commissioner, Camarillo, CA https://cdn.ventura.org/wpcontent/uploads/2020/09/AgComm-2019-Crop-Report-.pdf

Crase L, O'Reilly L, Dollery B. 2000. Water markets as a vehicle for water reform: The case of New South Wales. Aust J Agr Resour Ec 44(2):299-321.

Donoso G. 2006. Water markets: Case study of Chile's 1981 Wate Code. Cienc Investig Agrar 33(2):157-71
Fargher W. 2011. Responding to scarcity: Lessons from Australian Water Markets in Supporting Agricultural Productivity during Drought. Organization for Economic Cooperation and Development (OECD) Trade and Agriculture Directorate working pape

Foster T, Mieno T, Brozović N. 2020. Satellite-based monitoring of irrigation water use:

Assessing measurement errors and their implications for agricultural water management policy. Water Resour Res 56(11). https://do org/10.1029/2020WR028378
Garrick D, Lane-Miller C McCoy AL. 2011. Institutional innovations to govern environmental water in the Western United States: Lessons for Australia's Murray-Darling Basin. Econ Papers 30(2):167-84.

Garrick D, Siebentritt MA, Aylward B, et al. 2009. Water markets and freshwater ecosystem services: Policy reform and implementation in the Colombia and Murray-Darling Basins. Ecol Econ 69:366-79.

Grainger C, Costello C. 2014 Capitalizing property rights insecurity in natural resource assets. J Environ Econ Manag 67:224-40.
Heaney A, Dwyer G, Beare S, et al. 2006. Third-party effects of water trading and potential policy responses. Aust J Agr Resour Ec 50:277-93.

Hearne R, Easter KW. 1997. The economic and financial gains from water markets in Chile. Agr Econ 15:187-99. 